\title{
Ocorrência de Chlamydophila psittaci em pombos (Columba livia) na cidade de Salvador, Bahia
}

\author{
[Occurrence of the pigeon Chlamydophila psittaci in pigeons (Columba livia) within \\ the city of Salvador, Bahia] \\ D.C. Leal $^{1}$, V.B. Negrão ${ }^{1}$, F. Santos ${ }^{1}$, T.F. Raso ${ }^{2}$, S.M. Barrouin-Melo ${ }^{1}$, \\ C.R. Franke ${ }^{1 *}$
}

\author{
${ }^{1}$ Escola de Veterinária e Zootecnia - Universidade Federal da Bahia - LIVE-UFBA - Salvador, BA \\ ${ }^{2}$ Faculdade de Medicina Veterinária e Zootecnia - Universidade de São Paulo - FMVZ-USP - São Paulo, SP

\section{RESUMO}

A existência de populações numerosas de pombos (Columba livia) em centros urbanos, em quase todo o mundo, tem se tornado um risco à saúde pública em vista das zoonoses que podem transmitir. A infecção por Chlamydophila psittaci foi avaliada em pombos que frequentam áreas públicas, como praças, ruas e pontos turísticos na cidade de Salvador, Bahia, por meio da PCR em amostras de fezes frescas, suabes cloacais e orofaríngeos. O estudo revelou uma frequência de infecção por $C$. psittaci de 11,7\% (16/137) dos pombos, e oito dos 10 locais pesquisados apresentavam aves infectadas. A detecção de C. psittaci em amostras de cloaca e orofaringe foi maior $(15,8 \%$ - 3/19) que em amostras de fezes frescas $(11 \%$ 13/118). Os resultados demonstram a ocorrência de infecção por $C$. psittaci em pombos que habitam as áreas públicas da cidade de Salvador e apontam para a necessária elaboração de medidas de controle e monitoramento das populações de pombos urbanos, bem como de ações voltadas à conscientização da sociedade sobre os riscos à saúde pública.

Palavras-chave: pombo, Chlamydophila psittaci, saúde pública, controle populacional, zoonose

\begin{abstract}
The existence of numerous pigeon (Columba livia) populations in urban centers, in most of the world, has become a public-health risk given the zoonoses they can transmit. Infection with Chlamydophila psittaci was evaluated in pigeons that frequent public areas, such as squares, streets and tourist sites in the city of Salvador, through PCR from fresh feces samples, cloacal swabs and oropharyngeals. The study revealed a frequency of infection with C. psittaci of 11.7\% (16/137) in pigeons, and infected birds were found in eight of the ten locales researched. The detection of $\mathrm{C}$. psittaci in samples of cloaca and oropharyngs was greater $(15.8 \%$ - 3/19) than in the samples of fresh feces $(11 \%$ - 13/118). The results show the occurrence of infection with C. psittaciem in pigeons that live in public areas in the city of Salvador and points to the necessity of elaborating control and monitoring measures for the populations of urban pigeons as well as developing actions that will raise society's awareness of these risks to public health.
\end{abstract}

Keywords: pigeons, Chlamydophila psittaci, public health, population control, zoonoses

\section{INTRODUÇÃO}

Os pombos (Columba livia) possuem distribuição mundial e acentuada habilidade de adaptação ao ambiente urbano. Devido à alta densidade dessa espécie em parques e praças

Recebido em 22 de agosto de 2014

Aceito em 7 de abril de 2015

* Autor para correspondência (corresponding author)

E-mail: frankeufba@gmail.com públicas, seu significado para a saúde pública tem sido avaliado. O pombo pode atuar como reservatório de diversos microrganismos, e o fato de poder voar longas distâncias acentua seu potencial de dispersor de agentes patogênicos (Vázquez et al., 2010). Entre as doenças transmitidas por pombos, encontra-se a 
clamidiose, cujo agente é a Chlamydophila psittaci, bactéria intracelular obrigatória que acomete diversas espécies animais. Estudos realizados em São Paulo, Brasil, revelaram a ocorrência de C. psittaci em até $16,8 \%$ dos pombos examinados (Lima et al., 2010; Ferreira, 2012). Em outros países, levantamentos semelhantes registram frequências de infecção de até $96 \%$ (Vázquez et al., 2010).

Em hospedeiros infectados, a bactéria $C$. psittaci pode permanecer por longos períodos no interior dos macrófagos. Em condição de estresse, pode haver a recrudescência da doença e o hospedeiro pode eliminar de forma intermitente a bactéria nas secreções orofaríngeas e cloacais. Os sinais clínicos da clamidiose aviária são inespecíficos, a exemplo de: descargas nasais, diarreia amareloesverdeada, penas eriçadas, anorexia e conjuntivite (Harkinezhad et al., 2009). Os pombos, na maioria das vezes, não apresentam sinais clínicos da doença, no entanto podem atuar como fontes de infecção para aves de estimação, aves de produção e outros animais susceptíveis, inclusive para o homem (Vázquez et al., 2010).

O crescimento da população humana e a expansão urbana desordenada parecem contribuir para o aumento das populações de pombos nas cidades. Restringir o acesso dessas aves aos possíveis locais de abrigo e nidificação, bem como impedir o fornecimento de alimentos e promover a correta destinação dos resíduos orgânicos produzidos nas cidades, tem sido algumas das medidas adotadas para o controle populacional dos pombos (Nunes, 2003). A redução sustentável da população de pombos tem efeito benéfico no status de saúde dessas aves (Geigenfeind et al., 2012). Atualmente, a presença de grandes populações de pombos nos centros urbanos representa um grave problema de saúde pública. Tal fato justifica a realização de pesquisas e ações necessárias à ampliação do conhecimento sobre a epidemiologia da clamidiose. Desse modo, o objetivo do presente trabalho foi pesquisar a presença de $C$. psittaci em pombos que habitam áreas públicas na cidade de Salvador, Bahia.

\section{MATERIAL E MÉTODOS}

No período de junho a agosto de 2012, foram visitadas 27 áreas da cidade de Salvador, Bahia, como pontos turísticos e praças públicas (Fig. 1). Em oito dessas áreas, foi coletado, no chão, um total de 118 amostras de fezes frescas de pombos. Nas 19 áreas restantes, apesar de a maioria delas ter sido visitada por duas vezes em horários distintos, não foi possível a coleta de fezes, em razão da ausência de pombos no momento da visita ou da falta de aproximação deles, mesmo quando foi dado alimento (milho, pão e ração) para atraí-los e agrupá-los a fim de que defecassem numa área mais restrita, o que facilitaria a imediata coleta das fezes excretadas.

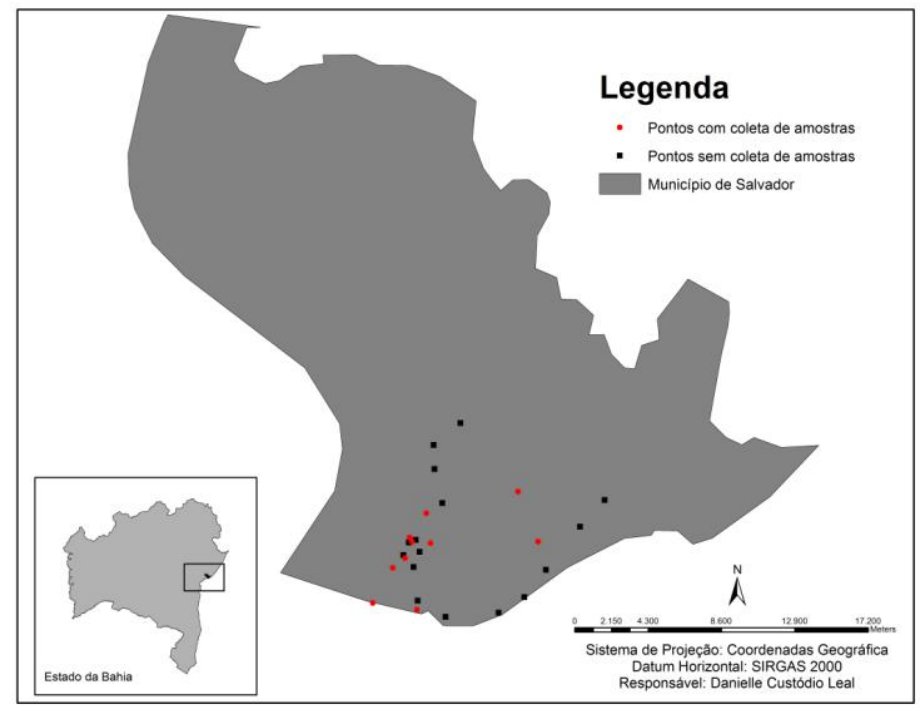

Figura 1. Locais visitados na cidade de Salvador, Bahia, para a coleta de amostras de fezes frescas de pombos entre junho e agosto de 2012. 
A pesquisa obteve a licença do Sistema de Informações da Biodiversidade (SISBIO) do Instituto Chico Mendes de Biodiversidade (ICMBio) e a aprovação da Comissão de Ética no Uso de Animais, Escola de Veterinária e Zootecnia da UFBA (CEUA-MEV, protocolo $\mathrm{n}^{\circ}$ $15 / 2010)$.

Em cada uma das oito áreas onde foi possível a coleta de amostras, após a distribuição do alimento, foi realizada a contagem dos pombos que estavam se alimentando. $\mathrm{O}$ número de fezes frescas coletadas correspondeu a cerca de $20 \%$ do total de pombos contados em cada área. As amostras foram coletadas do chão, com o uso de suabes estéreis, logo após serem defecadas, sendo acondicionadas em microtubos estéreis e mantidas refrigeradas. Aos microtubos foi adicionado $1 \mathrm{~mL}$ de solução fisiológica $(0,9 \%)$, que, em seguida, foi armazenada a $-80^{\circ} \mathrm{C}$ até posterior extração de DNA.

Com o objetivo de obter dados de frequência de infecção por $C$. psittaci em pombos em amostras da mucosa orofaríngea e da cloaca, foi coletado um total de 19 pombos na área do Centro de Triagem de Animais Silvestres (CETAS) e do Parque Zoobotânico Getúlio Vargas, ambos situados em áreas densamente habitadas pelas aves e com grande circulação de pessoas. A captura das aves foi realizada à noite, utilizando puçá, visto que essa espécie não possui boa visão noturna, o que facilitou o processo. As amostras foram obtidas por fricção da mucosa da orofaringe e da cloaca com suabes estéreis, os quais foram acondicionados em microtubos estéreis e mantidos refrigerados até o laboratório. Aos microtubos foi adicionado $1 \mathrm{~mL}$ de solução fisiológica $(0,9 \%)$ e, após homogeneização por cinco minutos, estocados a $-80^{\circ} \mathrm{C}$ até posterior extração de DNA. Nessas duas áreas, não foi possível coletar amostras de fezes no chão, pois os pombos não se aproximavam, mesmo após a distribuição de alimento.

O DNA das amostras de fezes foi extraído individualmente, utilizando-se o kit comercial Quiamp DNA Stool Mini Kit (Quiagen, Alemanha), seguindo instruções do fabricante, eluído em $200 \mu \mathrm{L}$ e estocado a $-80^{\circ} \mathrm{C}$. O DNA dos suabes foi extraído segundo Sambrook (2001), utilizando-se $250 \mu \mathrm{L}$ de cada amostra. Por fim, o pellet de DNA foi eluído em $30 \mu \mathrm{L}$ de Tris EDTA $(10: 0,1)$ e estocado a $-80^{\circ} \mathrm{C}$.

A snPCR para a detecção de $C$. psittaci foi realizada conforme descrito por Raso et al. (2006), com algumas modificações. Os primers utilizados foram com base no gene da proteína da membrana principal externa (MOMP) da bactéria. As sequências foram as seguintes: A (5'-CAGGACATCTTGTCTGGCTTTAA-3') e B (5'-GCAAGGATCG CAAGATC-3') para a primeira reação, produzindo um produto de 260pb, e $\quad$ C $\quad$ (5'-TTAG AGGTGAGTATGAAAAAACTC-3') e B para a segunda reação, produzindo um fragmento de $165 \mathrm{pb}$. Em volumes finais de $25 \mu \mathrm{L}$, as reações foram realizadas com $2 \mathrm{mM}$ de $\mathrm{MgCl}_{2}$ (Invitrogen, EUA), 0,2mM de dNTPs (Invitrogen, EUA), $1 \mathrm{U}$ de Taq Platinum polimerase (Invitrogen, EUA), $0,5 \mu \mathrm{M}$ de cada primer, $5 \mu \mathrm{L}$ de DNA genômico, para primeira reação, e, para a segunda reação, $1 \mu \mathrm{L}$ do produto da primeira. Controles positivos e negativos foram utilizados em cada lote de reação. As reações foram colocadas em termociclador a $94^{\circ} \mathrm{C}$ por 10 minutos, seguido de 35 ciclos de $94^{\circ} \mathrm{C}$ por 60 segundos, $54^{\circ} \mathrm{C}$ por 60 segundos (para primeira reação) e $52^{\circ} \mathrm{C}$ (para segunda reação) e $72^{\circ} \mathrm{C}$ por 90 segundos, com uma extensão final de $72^{\circ} \mathrm{C}$ por quatro minutos. Os produtos das PCRs foram corados com solução de Sybr Gold (Invitrogen, EUA) e submetidos à corrida eletroforética horizontal em gel de agarose $1,5 \%$, em tampão Tris borato EDTA (TBE), juntamente com o marcador de peso molecular $100 \mathrm{pb}$ (Invitrogen, EUA). Os resultados foram visualizados num transluminador e fotodocumentados (Biometra, Alemanha).

\section{RESULTADOS}

A frequência geral de detecção de $C$. psittaci foi de $11,7 \%(16 / 137)$, sendo $11 \%(13 / 118)$ nas amostras de fezes frescas e 15,8\% (3/19) nas amostras de suabes cloacais e orofaríngeos. Em $80 \%$ (8/10) dos locais avaliados foi possível encontrar aves infectadas por C. psittaci (Tab. 2). 
Tabela 2. Locais de coleta de amostras de fezes frescas, suabes cloacais e orofaríngeos de pombos e número de amostras com detecção de C. psittaci pela seminested PCR, na cidade de Salvador, Bahia

\begin{tabular}{lccc}
\multicolumn{1}{c}{ Local } & $\begin{array}{c}\mathrm{N}^{\mathbf{d}} \text { de } \\
\text { amostras } \\
\text { coletadas }\end{array}$ & $\begin{array}{c}\mathrm{N}^{\circ} \text { amostras positivas } \\
\text { na PCR }(\%)\end{array}$ & Tipo de amostra \\
\hline Porto de Salvador & 25 & $4(16 \%)$ & Fezes frescas \\
Praça da Piedade & 18 & $3(16,7 \%)$ & Fezes frescas \\
Mercado Modelo & 11 & $3(27,3 \%)$ & Fezes frescas \\
Farol da Barra & 16 & $1(6,3 \%)$ & Fezes frescas \\
Praça Almeida Couto & 12 & $1(8,3 \%)$ & Fezes frescas \\
Cabula & 11 & $1(9 \%)$ & Fezes frescas \\
Largo do Campo Grande & 12 & $0(0 \%)$ & Fezes frescas \\
Praça Thomé de Souza & 13 & $0(0 \%)$ & Fezes frescas \\
Subtotal & 118 & $13(11 \%)$ & Cloaca e orofaringe \\
Centro de Triagem de Animais & 11 & $2(18,2 \%)$ & Cloaca e orofaringe \\
Silvestres (CETAS) de Salvador & & $1(12,5 \%)$ & \\
Parque Zoobotânico Getúlio Vargas & 8 & $3(15,8 \%)$ & \\
Subtotal & 19 & $16(11,7 \%)$ & \\
\hline Total & 137 & & \\
\hline
\end{tabular}

\section{DISCUSSÃO}

Os resultados demonstram a presença de infecção por $C$. psittaci em $11,7 \%$ dos pombos avaliados na cidade de Salvador. Essa frequência é semelhante à registrada por Ferreira (2012), que observou uma prevalência de infecção por $C$. psittaci de $13 \%(31 / 240)$ nos pombos que habitavam armazéns de comércio de grãos em duas cidades do estado de São Paulo, bem como à registrada por Lima et al. (2011), que registraram a prevalência de infecção por $C$. psittaci de 16,8\% (40/238) nos pombos que coabitavam zoológicos, praças públicas e domicílios, também no estado de São Paulo.

Alguns estudos utilizaram amostras de fezes de pombos coletadas no chão para avaliar o status sanitário das populações locais por meio de técnicas moleculares. Tanaka et al. (2005) observaram C. psittaci em 22,9\% (106/463) das amostras de fezes obtidas de pombos no Japão. Heddema et al. (2006) determinaram uma prevalência de 7,9\% (26/331) em amostra de fezes de pombos em Amsterdã, Holanda. Um estudo com pombos em Madri, Espanha, registrou uma prevalência de $C$. psittaci em fezes de 53\% (Vázquez et al., 2010). A utilização de amostras de fezes para o diagnóstico de $C$. psittaci provavelmente subestima o status de infecção de uma população, em virtude de a bactéria ser eliminada de forma intermitente nas fezes das aves infectadas (Geigenfeind et al., 2012), o que pode contribuir para a ocorrência de resultados falsos negativos. A coleta de amostras em diferentes sítios, como amostras de orofaringe e cloaca, e em momentos diferentes aumenta a chance de diagnóstico de infecção por C. psittaci (Andersen, 1996). Outro fator a ser considerado é a qualidade da amostra obtida. No presente estudo, foi coletada uma amostra representativa da população de pombos presente no momento da coleta; além disso, houve um grande cuidado para que as fezes fossem coletadas assim que defecadas. Fezes ressecadas, misturadas com restos de alimentos ou material do solo representam os maiores problemas na obtenção adequada desse tipo de amostra.

Alguns estudos sugerem que a excreção de $C$. psittaci também varia em razão da época do ano. Heddema et al. (2006), na Holanda, analisaram amostras de fezes obtidas no período préreprodutivo e durante o período reprodutivo, e observaram que a prevalência de amostras positivas durante o período reprodutivo, $10 \%$ $(18 / 171)$, foi duas vezes maior que no período pré-reprodutivo, $5 \%(8 / 160)$. O período de maior excreção de $C$. psittaci nas fezes dos pombos ocorreu durante no período reprodutivo, na primavera (maio), enquanto o período préreprodutivo ocorreu no inverno (fevereiro e março). Lublin et al. (1999) também observaram que a eliminação de $C$. psittaci aconteceu de 
forma sazonal, havendo aumento da excreção do agente nos períodos quentes do ano.

No Brasil, em um estudo sazonal realizado ao longo de um ano no estado de São Paulo, de 240 amostras de suabe cloacal obtidas de pombos, $C$. psittaci foi detectada em $10,8 \%$ das amostras provenientes de aves capturadas na estação seca e em $15,8 \%$ na estação chuvosa, não havendo diferença estatística entre as estações analisadas (Ferreira, 2012). No presente estudo, as amostras foram obtidas entre os meses de junho e agosto, período mais chuvoso do ano na cidade Salvador.

Todas as áreas onde houve coleta de amostras de fezes apresentam intensa circulação de pessoas, sendo quatro áreas pontos turísticos importantes da cidade de Salvador e três próximas ao setor de comércio mais movimentado da cidade. O Porto de Salvador apresentou a maior concentração de aves entre os locais avaliados, as quais se encontram em estreito convívio com os trabalhadores portuários, expondo-os ao risco de infecção ou de contaminação de gêneros alimentícios transportados pelos navios. No Parque Zoobotânico e no CETAS, onde os pombos foram efetivamente capturados, a presença de pombos infectados por C. psittaci representa uma fonte de infecção para as demais espécies de aves ali mantidas, algumas, inclusive, ameaçadas de extinção, bem como para os funcionários envolvidos. Na Bélgica, um estudo demonstrou que a maior frequência de casos humanos de infecção por C. psittaci ocorria em pessoas com histórico de contato com espécies de aves das ordens Psittaciformes e Columbiformes, sendo menos comum naquelas que tinham contato com aves de outras espécies (Harkinezhad et al., 2009).

\section{CONCLUSÃO}

A detecção da presença de pombos infectados por $C$. psittaci na cidade de Salvador revela uma preocupação em relação à saúde da população humana e de animais que convivem nos espaços públicos, sendo necessária a realização de ações visando ampliar conhecimento sobre a epidemiologia dessa zoonose e popularizar as informações sobre os fatores de risco de transmissão e medidas preventivas, bem como a orientação da população por meio de práticas de educação ambiental para implementação de medidas de controle populacional dessa espécie sinantrópica.

\section{AGRADECIMENTOS}

Ao Conselho Nacional de Desenvolvimento Científico e Tecnológico (CNPq), pelo apoio financeiro ao projeto (Processo no 476891/20108), e à Coordenação de Aperfeiçoamento de Pessoal de Nível Superior (Capes), pela bolsa de doutorado concedida.

\section{REFERÊNCIAS}

ANDERSEN, A.A. Comparison of pharyngeal, fecal, and cloacal samples for the isolation of Chlamydia psittaci from experimentally infected cockatiels and turkeys. J. Vet. Diagn.Invest., v.8, p.448-450, 1996.

FERREIRA, V. L. Avaliação sazonal do perfil sanitário de pombos-domésticos (Columba livia) em áreas de armazenamento de grãos e sementes no Estado de São Paulo. 2012. 78f. Dissertação (Mestrado em Ciências) - Faculdade de Medicina Veterinária e Zootecnia, Universidade de São Paulo, São Paulo, SP.

GEIGENFEIND, I; VANROMPAY, D.; HAAGWACKERNAGEL, D. Prevalence of Chlamydia psittaci in the feral pigeon population of Basel, Switzerland. J Med Microbiol., v.61, p.261-265, 2012.

HARKINEZHAD, T.; GEENS,T.; VANROMPAY, D. Chlamydophila psittaci infections in birds: A review with emphasis on zoonotic consequences. Vet. Microbiol., v.135, p.68-77, 2009.

HEDDEMA E.R.; TER SLUIS S.; BUYS J. et al. Prevalence of Chlamydophila psittaci in Fecal Droppings from Feral Pigeons in Amsterdam, The Netherlands. Appl. Environ. Microbiol., v.72, p.4423-4425, 2006.

LIMA, V. Y., LANGONI, H., SILVA, A. V. et al. Chlamydophila psittaci and Toxoplasma gondii infection in pigeons (Columba livia) from São Paulo State, Brazil. Vet. Parasitol., v.175, p.09-14, 2011.

LUBLIN, A.; LEIDERMAN, E.; WEISMAN, Y. Seasonal dependence of Chlamydia psittaci shedding in pigeons. Isr. J. Vet. Med., v.54, p.99$102,1999$. 
NUNES, V.F.P. Pombos urbanos: o desafio de controle. Biológico, v.65, p.89-92, 2003.

RASO, T. F.; SEIXAS, G. H. F.; GUEDES, N. M. R. et al. Chlamydophila psittaci in free-living Blue-fronted Amazon parrots (Amazona aestiva) and Hyacinth macaws (Anodorhynchus hyacinthinus) in the Pantanal of Mato Grosso do Sul, Brazil. Vet. Microbiol., v.117, p.235-241, 2006.

SAMBROOK, J.; FRITCH, E. F.; MANIATIS, T. Molecular Cloning: A Laboratory Manual. 3.ed. NewYork: Cold Spring Harbor Laboratory Press, 2001.
TANAKA C.; MIYAZAWA T.; WATARAI M. et al. Bacteriological Survey of Feces from Feral Pigeons in Japan. J. Vet. Med. Sci., v. 7, p.951953, 2005.

VAZQUEZ B.; ESPERON F.; NEVES E. et al. Screening for several potential pathogens in feral pigeons (Columbia livia) in Madrid. Acta Vet. Scand. v.52, 1-6, 2010. 